\title{
STRUCTURES OF TWO NEW BITTER PRINCIPLES ISOLATED FROM A THAI MEDICINAL PLANT, VERNONIA
} EXTENSA D. C.

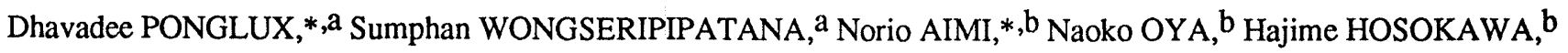
Joju HAGINIWA ${ }^{b}$, and Shin-ichiro SAKAI ${ }^{b}$

Faculty of Pharmaceutical Sciences, Chulalongkorn University, ${ }^{a}$ Bangkok 10500, Thailand and Faculty of Pharmaceutical Sciences, Chiba University, b 1-33 Yayoi-cho, Chiba 260, Japan

From the Thai medicinal plant, Vernonia extensa, two sterol glucosides, VE-1 and VE-2, were isolated. Their structures were proved to be closely related to the new class of bitter principles recently found in an African species of Vernonia.

KEYWORDS Vernonia extensa; Compositae; sterol glycoside; bitter principle; Thai medicinal plant

Vernonia extensa D. C. is a woody plant of the family Compositae native to northern Thailand. The bark and stem taste quite bitter and are used by the local people as a tonic drink for stimulation of physical activity. This plant was collected on the occasion of a joint botanical survey by the groups of Thai and Japanese authors. Recently we learned that Koshimizu et al. of Kyoto University have been studying the constituents of a species of Vernonia endemic in Africa. ${ }^{1)}$ They noticed the importance of this plant in their observation of feeding behaviors of chimpanzees and other wild animals in the forests of the African continent. In this communication, we report our independent study on the constituents of a Thai species of Vernonia.

The methanol extract of the stem bark was divided into water soluble and insoluble parts. The water insoluble part was dissolved in $\mathrm{CHCl}_{3}-\mathrm{MeOH}$ (95:5) and the soluble component was chromatographed over $\mathrm{SiO}_{2}$. After extensive purification of the fraction eluted with $\mathrm{CHCl}_{3}-\mathrm{MeOH}$ (4:1), two bitter components named VE-1 (1) and VE-2(2) were obtained. Conventional acetylation afforded the corresponding acetates, VE-1-acetate (3) and VE-2-acetate (4).

VE-1-acetate (3) $\left.{ }^{2}\right) \mathrm{mp} 199-200{ }^{\circ} \mathrm{C}\left(\mathrm{dec}\right.$.), $\mathrm{C}_{47} \mathrm{H}_{66} \mathrm{O}_{17}$, showed the UV spectrum having absorption maxima at 235 , 242 , and $249 \mathrm{~nm}$, typical of trans heteroannular $\Delta^{7,9(11)}$ diene in a sterol framework. The ${ }^{13} \mathrm{C}$-NMR spectrum clearly demonstrated the presence of a fully acetylated glucose moiety linked to $\mathrm{C}-3$ hydroxyl group with $\beta$ glycosidic bond.
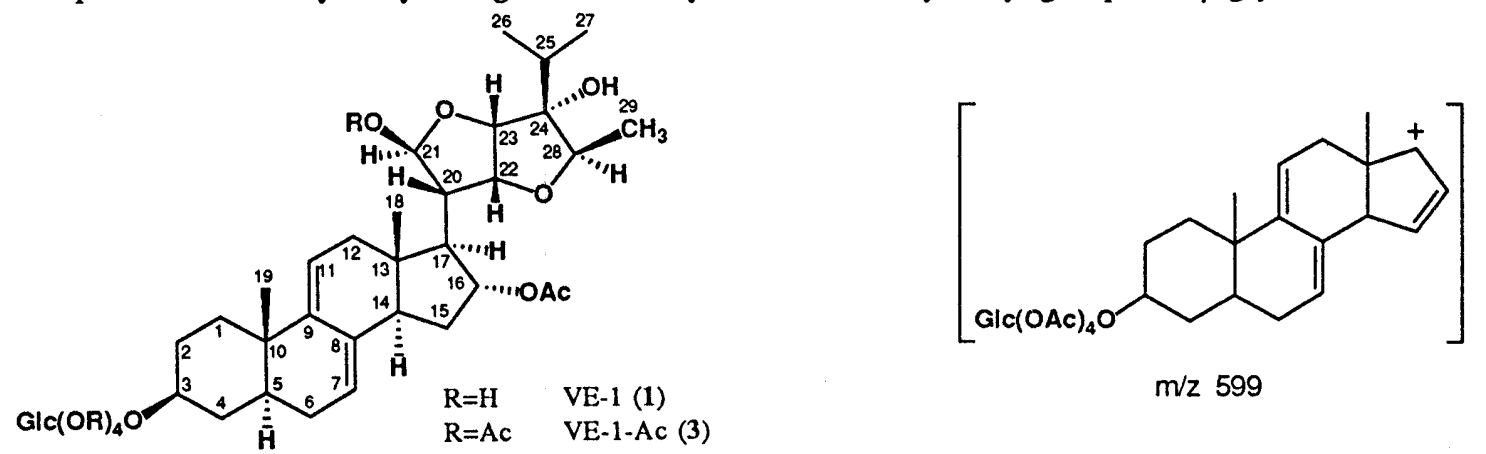

The FAB-MS of 3 showed fragment ion of $\mathrm{m} / \mathrm{z} 599$ besides the expected molecular ion peak at $\mathrm{m} / \mathrm{z} 925(\mathrm{M}+\mathrm{Na})^{+}$. Assignments of observed ${ }^{13} \mathrm{C}$-NMR signals to the sterol framework carbons, $\mathrm{C}-1$ through $\mathrm{C}-19$ with oxygen functions at $\mathrm{C}-3 \beta$ and $\mathrm{C}-16 \alpha$, were made by using ${ }^{1} \mathrm{H}_{-}{ }^{13} \mathrm{C} \mathrm{COSY}$ and other $1 \mathrm{D}$ - and $2 \mathrm{D}$ - pulse techniques, referring to empirical calculations as well. ${ }^{3)}$

Deduction of this fundamental moiety from the molecular formula revealed the presence of the side chain with the composition of $\mathrm{C}_{10} \mathrm{H}_{17} \mathrm{O}_{4}$. The unique structure of this part was studied by ${ }^{1} \mathrm{H}$ - and ${ }^{13} \mathrm{C}-\mathrm{NMR}$ spectra (1D and 2D). Thus the ${ }^{1} \mathrm{H}$-NMR spectrum showed the presence of a hemiacetal proton $\mathrm{H}-21$ at $\delta 6.06$ as a doublet. The coupling constant, $\mathrm{J}=$ $6.6 \mathrm{~Hz}$, indicated trans relationship of $\mathrm{H}-21$ with the neighboring $\mathrm{H}-20$ proton. Then a series of all three cis-related protons, $\mathrm{H}$ 20 ( $\delta 2.47$, ddd, J=4.5, 6.6, $11.3 \mathrm{~Hz}), \mathrm{H}-22(\delta 4.51$, dd, J=3.6, $4.5 \mathrm{~Hz})$, and $\mathrm{H}-23(\delta 4.41, \mathrm{~d}, \mathrm{~J}=3.6 \mathrm{~Hz}$ ), were evidenced. On the 
neighboring carbon, C-24, an isopropyl group and a non acetylable tertiary hydroxyl group were allocated. A doublet methyl group $(\delta 1.18, \mathrm{~J}=6.6 \mathrm{~Hz})$ was reasonably placed on $\mathrm{C}-28$, the proton on the same carbon (H-28) being observed at $\delta 3.83$ as a double double doublet (quartet) with the coupling constant of $6.6 \mathrm{~Hz}$. The carbon skeletal composition is comprehended by the frequently encountered bis-homo sterols having two carbons, C-28 and C-29, on C-24 of the normal sterol side chain.

The relative stereochemistry within the side chain moiety was proved by NOE spectra. Thus NOE's were observed between $\mathrm{H}-21 \alpha$ and $\mathrm{H}-28 \alpha$ and between 26-Me and $\mathrm{H}-23$.

An important, and most gratifying clue to the next question of determination of relative stereochemistry between C-17 and C-20 came from the above mentioned research work accomplished by Koshimizu et al. of Kyoto University. 1) They succeeded in clarifying the structure of one of their compounds through X-ray crystallography. Our compounds were from a plant of the same genus and obviously belong to the same structural class. Therefore it will be quite natural to postulate the same relative stereochemistry at $\mathrm{C}-17$ and $\mathrm{C}-20$. Thus the whole structure of 3 can be depicted as shown above.

Next, 3 was submitted to deacetylation using $\mathrm{NaOMe}-\mathrm{MeOH}$ at room temperature. The acetyl group on 16- $\alpha$ hydroxyl group resisted deacetylation under this condition. It was then clarified that the resulting compound was identical with natural VE-1 (1).4)

The natural VE-1 (1) showed the IR absorption band at $1735 \mathrm{~cm}^{-1}$ indicating the presence of an ester group in the molecule. ${ }^{1} \mathrm{H}$-NMR signal $(\delta 2.01,3 \mathrm{H}, \mathrm{s})$ and ${ }^{13} \mathrm{C}$-NMR signal $(\delta 172.3)$ strongly demonstrated that this compound contained one acetoxyl group in the molecule. The position of the acetoxyl group was allocated on $\mathrm{C}-16$ through examination of ${ }^{1} \mathrm{H}$ and ${ }^{13} \mathrm{C}$-NMR spectra. It was quite evident that glucose moicty was free from the acetyl group. The H-21 signal of natural VE-1 appeared at $\delta 5.42$, a far higher field than the corresponding signal in the acetate $(3)(\delta 6.06)$, indicating the hemiacetal hydroxyl group was also free. This indicated the presence of the acetyl group on $16 \alpha-\mathrm{OH}$ of VE-1.

The UV spectrum of the second component VE-2 (2) ${ }^{5)}, \mathrm{C}_{35} \mathrm{H}_{52} \mathrm{O}_{11}$, indicated the presence of the same conjugated heteroannular diene as 1 . The ${ }^{13} \mathrm{C}$-NMR spectrum demonstrated the same carbon skeletal structure of the sterol framework, the difference being the absence of an oxygen function on C-16. The structure of the side chain part of the molecule was conclusively elucidated as shown.

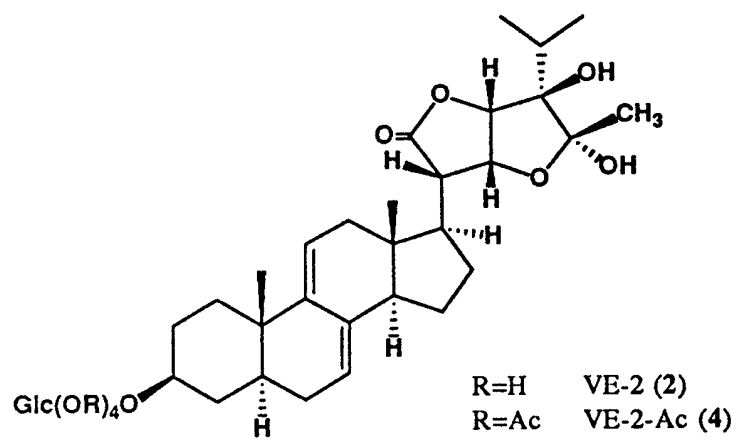

In accordance with this structure, the ${ }^{13} \mathrm{C}$-NMR signal due to a lactone carbonyl at $\mathrm{C}-21$ was observed at $\delta 178.8$. The ${ }^{1} \mathrm{H}-\mathrm{NMR}$ signal of the $\mathrm{C}-29$ methyl group appeared as a singlet at $\delta 1.47$. The ${ }^{1} \mathrm{H}-\mathrm{NMR}$ indicated the absence of proton on C-28. The hemiketal nature of the corresponding carbon, C-28, was envisaged as a singlet at $\delta 108.6$ on ${ }^{13} \mathrm{C}-\mathrm{NMR}$ spectrum. The relative stereochemistry of the side chain moiety was studied by NOE spectroscopy. Thus NOE's were observed between $20-\mathrm{H}$ and $22-\mathrm{H}$, and between $22-\mathrm{H}$ and $23-\mathrm{H}$, whereas no NOE was observed between $23-\mathrm{H}$ and protons in the isopropyl group. These observations indicated the depicted stereostructure. $\left.{ }^{6}\right)$

The ${ }^{13}$ C-NMR shift values of 4 supported the correctness of the proposed structure. 7 )

Here again there remains the problem of relative stereochemistry between $\mathrm{C}-17$ and $\mathrm{C}-20$, and the depicted structure is based on the X-ray result of Koshimizu's research work, as stated above. 1)

ACKNOWLEDGMENTS The authors thank the Ministry of Education, Science and Culture, Japan, for financial support through the grants of the Monbusho International Scientific Research Program: Joint Research 01044025 and University-to-University Cooperative Research 03045017. 


\section{REFERENCES AND NOTES}

1) H. Ohigashi, M. Jisaka, T. Takagaki, H. Nozaki, T. Tada, M. A. Huffman, T. Nishida, M. Kaji, and K. Koshimizu, Agr. Biol. Che'm., 55, 1201 (1991)

2) Colorless prisms, mp 199-200 ${ }^{\circ} \mathrm{C}$ (dec.) from $\mathrm{MeOH}$. Anal. Found; C, 62.33, H, 7.20; Calcd. for $\mathrm{C}_{47} \mathrm{H}_{66} \mathrm{O}_{17}$; $\mathrm{C}, 62.51$, $\mathrm{H}, 7.37$. UV $\lambda \max (\mathrm{EtOH}) \mathrm{nm} ; 235,242$, and 249. IR vmax (KBr); 3500, 2950, 1750, 1230, $1040 \mathrm{~cm}^{-1}$. ${ }^{13} \mathrm{C}-\mathrm{NMR}$ (125 MHz, $\mathrm{CDCl}_{3}$ ) 8; 13.2 (C-18), 13.6 (C-29) 17.0 (C-26), 17.7 (C-27), 19.3 (C-19), 20.6 - 21.4 (6 x CO- $\left.\mathrm{CH}_{3}\right), 29.4$ (C-2), 29.4 (C-25), 29.9 (C-6), 33.1 (C-15), 34.2 (C-4), 34.5 (C-1), 35.9 (C-10), 39.0 (C-5), 40.2 (C-12), 42.7 (C-13), 48.7 (C-14), 51.0 (C-20), 53.5 (C-17), 62.2 (C-6'), 68.6 (C-4'), 71.6 (C-2'), 71.7 (C-5'), 72.9 (C-3'), 77.3 (C-16), 79.4 (C-3), 81.7 (C-22), 82.0 (C-28), 82.2 (C-24), 83.8 (C-23), 99.7 (C-1'), 99.9 (C-21), 117.3 (C-11), 121.4 (C-7), 134.6 (C-8), 143.9 (C-9), and 169.3 - $170.7\left(6 \times \mathrm{CO}^{\left.-\mathrm{CH}_{3}\right)}{ }^{1} \mathrm{H}-\mathrm{NMR}\left(500 \mathrm{MHz}, \mathrm{CDCl}_{3}\right) \delta ; 0.57\left(3 \mathrm{H}, \mathrm{s}, 18-\mathrm{H}_{3}\right), 0.87(3 \mathrm{H}, \mathrm{s}\right.$, 19- $\left.\mathrm{H}_{3}\right), 0.91\left(3 \mathrm{H}, \mathrm{d}, \mathrm{J}=6.9 \mathrm{~Hz}, 26-\mathrm{H}_{3}\right), 1.01\left(3 \mathrm{H}, \mathrm{d}, \mathrm{J}=6.6 \mathrm{~Hz}, 27-\mathrm{H}_{3}\right), 1.18\left(3 \mathrm{H}, \mathrm{d}, \mathrm{J}=6.6 \mathrm{~Hz}, 29-\mathrm{H}_{3}\right), 1.26$ (ddd, J=12.1, 12.1,12.1 Hz, 4-Hb), 1.31 (m, 1-H), $1.39(\mathrm{~m}, 14-\mathrm{H}), 1.58$ (dddd, J=15.4, 15.4,15.4,4.1 Hz, 2-Hb), 1.69 (br.d, J=12.1 Hz, 4-Ha), 1.76 (dd, J=7.4,13.8 Hz, 6-Hb), $1.88(\mathrm{~m}, 15-\mathrm{H}), 1.88(\mathrm{~m}, 12-\mathrm{Hb}), 1.88(\mathrm{~m}, 25-\mathrm{H}), 1.97(\mathrm{~m}, 15-\mathrm{H}), 1.97$ (m, 6$\mathrm{Ha}), 1.97(\mathrm{~m}, 2-\mathrm{Ha}), 1.97\left(\mathrm{~m}, 1-\mathrm{H}^{\prime}\right), 2.01-2.10\left(6 \times \mathrm{CO}-\mathrm{CH}_{3}\right), 2.13$ (dd, J=6.6,11.3 Hz, 17-H), 2.20 (d, J=16.8 Hz, 12 Ha) 2.47 (ddd, J=4.5,6.6,11.3 Hz, 20-H), $2.54(\mathrm{~m}, 5-\mathrm{H}), 2.70$ (1 H,s, 24-OH; disappered on $\mathrm{D}_{2} \mathrm{O}$ addition), 3.54 (m, 3-H), 3.69 (m, 5'-H), 3.83 (ddd, J=6.6,6.6,6.6 Hz, 28-H), 4.12 (dd, J=4.95, $12.2 \mathrm{~Hz}, 6^{\prime}-\mathrm{H}$ ), 4.26 (dd, J=2.33,12.2 Hz, 6'-H), $4.41(\mathrm{~d}, \mathrm{~J}=3.6 \mathrm{~Hz}, 23-\mathrm{H}), 4.51$ (dd, J=3.6,4.5 Hz, 22-H), 4.60 (d,J=8.0 Hz, 1'-H), 4.95 (dd, J=8.0,9.6 Hz, 2'-H), 5.07 (dd, $\left.\mathrm{J}=9.6,9.9 \mathrm{~Hz}, 4^{\prime}-\mathrm{H}\right), 5.20$ (dd, J=9.4,9.6 Hz, 3'-H), 5.34 (dd, J=7.7,7.7 Hz, 16-H), 5.34 (br.s, 7-H), 5.42 (d, J=6.0 Hz, $11-$ $\mathrm{H}), 6.06(\mathrm{~d}, \mathrm{~J}=6.6 \mathrm{~Hz}, 21-\mathrm{H})$.

3 a) H. Beierbeck and J. K. Saunders, Can. J. Chem., 53, 1307 (1975); b) W. B. Smith, Carbon-13 Specroscopy of Steroids in "Annual Reports on NMR Spectroscopy", Vol. 8, Ed. G. A. Webb, Academic Press, 1978, London, p. 199.

4) Colorless granules, mp 226-227 ${ }^{\circ} \mathrm{C}$. Anal. Found; $\mathrm{C}, 61.76, \mathrm{H}, 7.81$; Calcd. for $\mathrm{C}_{37} \mathrm{H}_{56} \mathrm{O}_{12} \cdot 3 / 2 \mathrm{H}_{2} \mathrm{O}$; $\mathrm{C}, 61.73, \mathrm{H}$, 8.26. UV $\lambda \max (\mathrm{MeOH}) \mathrm{nm} ; 235,242$, and $249 .{ }^{13} \mathrm{C}-\mathrm{NMR}\left(125 \mathrm{MHz}, \mathrm{CD}_{3} \mathrm{OD}\right) \delta ; 14.4(\mathrm{C}-18), 14.4(\mathrm{C}-29), 17.5$ (C26), 17.7 (C-27), 19.8 (C-19), 21.7 (CO- $\left.\mathrm{CH}_{3}\right), 30.6$ (C-2), 31.0 (C-6), 32.4 (C-25), 34.4 (C-15), 35.0 (C-4), 35.9 (C1), 37.1 (C-10), 40.4 (C-5), 42.7 (C-12), 43.8 (C-13), 49.9 (C-14), 50.2 (C-20), 52.7 (C-17), 62.8 (C-6'), 71.7 (C-4'), 75.1 (C-2'), 77.9 (C-5'), 78.1 (C-3'), 78.6 (C-16), 79.0 (C-3), 82.8 (C-22), 83.4 (C-24), 85.8 (C-28), 89.0 (C-23), 99.8 (C-21), 102.4 (C-1'), 120.0 (C-11), $122.3(\mathrm{C}-7), 136.3$ (C-8), $145.0(\mathrm{C}-9)$, and $172.3\left(\mathrm{CO}^{-\mathrm{CH}} 3\right)$.

5) Amorphous powder, $\mathrm{C}_{35} \mathrm{H}_{52} \mathrm{O}_{11}$, FAB-MS m/z $649(\mathrm{M}+1) .{ }^{13} \mathrm{C}-\mathrm{NMR}\left(100 \mathrm{MHz}, \mathrm{CD}_{3} \mathrm{OD}\right) \delta ; 12.6(\mathrm{C}-18), 16.4(\mathrm{C}-26)$, 18.7 (C-27), 20.0 (C-19), 23.4 (C-29), 24.2 (C-15), 28.9 (C-25), 29.4 (C-16), 30.6 (C-2), 31.1 (C-6), 35.1 (C-4), 36.6 (C-1), 37.1 (C-10), 40.1 (C-5), 42.4 (C-12), 43.3 (C-13), 47.8 (C-17), ca.49 (hidden under solvent signal, C-20), 52.7 (C14), 62.8 (C-6') 71.7 (C-4'), 75.2 (C-2'), 77.9 (C-5'), 78.1 (C-3'), 78.7 (C-22), 79.0 (C-3), 85.3 (C-24), 87.8 (C-23), 102.4 (C-1'), 108.6 (C-28), 120.7 (C-11), 121.1 (C-7), 137.8 (C-8), 144.8 (C-9), 178.8 (C-21).

6) In ${ }^{1} \mathrm{H}$ - and ${ }^{13} \mathrm{C}$-NMR spectra of 2 some peaks are accompanied by small signals due to equilibrated anomers at the hemiketal carbon, $\mathrm{C}-28$. Stereochemical study was conducted on the major isomer.

7) Amorphous powder, $\mathrm{C}_{43} \mathrm{H}_{60} \mathrm{O}_{15}$, FAB-MS; m/z839(M+Na).. ${ }^{13} \mathrm{C}-\mathrm{NMR}\left(100 \mathrm{MHz}, \mathrm{CDCl}_{3}\right) \delta ; 12.2(\mathrm{C}-18), 15.0(\mathrm{C}-$ 26), 17.9 (C-27), 19.4 (C-19), 20.6 - 20.8 (4 x CO- $\mathrm{CH}_{3}$ ), 23.0 (C-15), 25.2 (C-29), 27.9 (C-25), 28.1 (C-16), 29.4 (C2), 29.9 (C-6), 34.3 (C-4), 34.6 (C-1), 35.8 (C-10), 39.1 (C-5), 41.1 (C-12), 42.1 (C-13), 46.1 (C-17), 48.0 (C-20), 51.2 (C-14), 62.2 (C-6') 68.6 (C-4'), 71.6 (C-5'), 71.6 (C-2'), 72.9 (C-3'), 78.4 (C-22), 79.6 (C-3), 82.8 (C-24), 85.3 (C-23), 99.7 (C-1'), 107.0 (C-28), 119.5 (C-11), 120.1 (C-7), 136.2 (C-8), 143.2 (C-9), 169.4 - 170.8 (4 x CO-CH3), and 175.8 (C-21). 